\title{
Concussion return-to-play behaviour of South African Rugby Union (SA Rugby) Youth Week players: a pilot study
}

\author{
J Brown, ${ }^{1,2}$ PhD; K Malloch-Brown, ${ }^{1}$ BSc (Med)(Hons) \\ Biokinetics, W Viljoen, ${ }^{1,3}$ PhD, CSCS, C Readhead, ${ }^{1,3}$ BSc \\ Physiotherapy, S Mc Fie, ${ }^{1}$ BSc (Hons), Neuroscience
}

${ }^{1}$ Division of Exercise Science and Sports Medicine, Department of Human Biology, Faculty of Health Sciences, University of Cape Town, Cape Town, South Africa;

${ }^{2}$ Department of Public \& Occupational Health and the EMGO Institute for Health and Care Research, VU University Medical Center, Amsterdam, The Netherlands.

3 South African Rugby Union, SARU House, Plattekloof, 163 Uys Krige Road, Cape Town, South Africa

\section{Corresponding author: J Brown (jamesbrown06@gmail.com)}

Introduction: BokSmart has disseminated Graduated Return-to-Play (GRTP) guidelines for concussions management to all, but specifically coaches, in South Africa. Medical clearance before returning to play (RTP) is poorly adhered to in the GRTP steps. This study explored barriers to compliance with medical clearance prior to RTP.

Methods: Players who suffered a concussion during the 2014/2015 South African Rugby Youth Week Tournaments were followed-up telephonically until RTP. Semi-structured interviews were conducted to explore enablers/barriers to seeking/not seeking medical clearance before RTP.

Results: Of those who did not seek medical clearance (47\%), $80 \%$ indicated that the player/parent or coach felt this was unnecessary. Of those who did seek medical clearance, $65 \%$ reported they were instructed to do so either by the tournament doctor who diagnosed the injury or by the school coach.

Conclusion: Besides coaches, parents and medical doctors have an important influence on players' RTP behaviour. The findings of this pilot study need to be repeated in a larger cohort.

Keywords: injury management, head injury, youth, football, South Africa

\section{S Afr J Sports Med 2016;28(2):43-45. DOI: 10.17159/2078-516X/2016/v28i2a1311}

Rugby union ('rugby') players are at a high risk of sustaining injuries, including concussion. [1] Concussion is a brain injury that is defined as “a complex pathophysiological process affecting the brain, induced by biomechanical forces", and is an "evolving injury in the acute phase with rapidly changing clinical signs and symptoms". ${ }^{[1]}$ Moreover, youth athletes are more susceptible to concussion and its effects. ${ }^{[1]}$

As a result, World Rugby has published concussion management guidelines, to which all rugby-playing nations need (http://playerwelfare.worldrugby.org/concussion). BokSmart is South Africa's national rugby safety programme. Since 2011, it has been compulsory for all South African coaches and referees to attend a biennial BokSmart workshop. [2] Workshops include concussion education and provide attendees with free concussion resources (DVDs, manual, information pieces and a pocket-sized on-field 'Concussion Guide'). Additional concussion information is available online: www.boksmart.com/concussion.

Included in all educational material is the Graduated Return-to-Play (GRTP) protocol, which is based on the Consensus Statement for Concussion in Sport [1] and World Rugby's rules and regulations. All formats emphasise the importance of being cleared by a medical doctor before returning to play.

At the 2011-2014 annual SA Rugby Youth Week tournaments, concussion comprised $31 \%$ of all time-loss injuries at a rate of 6.8/1000 player exposure hours. ${ }^{[3]}$ Of those players, only $14 \%(\mathrm{n}=7$ of 50$)$ received any follow-up treatment before returning to play. ${ }^{[4]}$ The authors suggested that a lack of medical insurance might explain this finding. ${ }^{[4]}$ However, a study of youth rugby in Australia found similarly low levels of compliance to GRTP guidelines suggesting that this might not be a unique problem. ${ }^{[5]}$ Although both studies speculated as to why players did not follow GRTP guidelines, to these authors' knowledge no study has explored this further.

Therefore the aim of this pilot study was to explore the reasons why players did not adhere to the guideline requiring medical clearance before returning to play.

\section{Methods}

As part of an ongoing project, injury surveillance was conducted at four SA Rugby Youth Week tournaments in 2014 and 2015: Craven Week under-13, Grant Khomo under16, Academy Week under-18, and Craven Week under-18. As previously mentioned, ${ }^{[4]}$ a tournament medical doctor was available at each tournament to assess and diagnose all tournament-sustained injuries. Players with a "time-loss" injury (an injury resulting in more than one missed training/matches) were followed up telephonically until they returned to play. [4] Only players with concussions were included in the present analysis $(n=40)$. The players' parents/legal guardians provided written informed consent to record and analyse the data. SA Rugby and the UCT Human Research Ethics Committee (HREC ref: 438/2011) granted permission to analyse the concussion data captured on the SA Rugby database.

Forty concussions were recorded over the two years' tournaments. Owing to the small sample size and no outcome differences between 2014 and 2015, the data were grouped for analysis. Eight of these injuries (20\%) could not be followed up for various reasons, including the injured player/legal 
guardian being unreachable.

A University of Cape Town (UCT) researcher performed semi-structured telephonic interviews with the players' parents/legal guardians $(n=23,72 \%)$, and, in exceptional cases, with the players themselves when the parents/legal guardians were not contactable $(n=9,28 \%)$. The interview aimed to explore reasons for compliance or non-compliance, to seeking medical clearance before returning to play after the tournament. SM, KMB, and JB compiled the questionnaire, which was reviewed by several sport scientists, rugby medical practitioners, and SA Rugby's medical department.

The questions probed whether the injured player had medical insurance and if they had had any previous experiences with concussions. They were then asked if the player had received medical clearance before returning to play. Depending on the answer, they were questioned on why they did or did not seek medical clearance. For ease of recording, the interviewer had nine categories for the reasons provided. The respondents were never prompted. If the reason provided did not fall within the nine categories, it was captured as "other". Code categorisation was repeated twice by $\mathrm{KMB}$ and once by JB to ensure sufficient reliability. Frequencies were calculated to identify the most common barriers to compliance. Chi-squared tests with Fisher's exact were performed to assess if frequencies were significantly different $(\mathrm{P}<0.05)$ between those who did or did not seek medical clearance before returning to play.

\section{Results}

The majority of concussed players analysed $(53 \%, n=17)$ sought medical clearance before returning to play.

Although the number of players without medical insurance was small, there were no differences in the proportion of players seeking medical clearance, between those with and without medical insurance (without medical insurance: $50 \%, n=3$; with medical insurance: $54 \%, n=14$; $\mathrm{p}=0.61$ ). Similarly, previous history of concussion was not associated with seeking medical clearance before returning to play (without a previous history of concussion: $57 \%, \mathrm{n}=12$; with a previous history of concussion: $46 \%, \mathrm{n}=5$; $\mathrm{p}=0.40$ ).

The most commonly mentioned barrier to seeking medical clearance before returning to play was the perception that it "was not necessary" $(80 \%, \mathrm{n}=12$, Table 1$)$. In the majority of cases $(92 \%, \mathrm{n}=11)$ a parent or player decided that it was unnecessary. In one of these cases, the parent's interpretation of only the tournament medical doctor's advice was a three week break from contact sport, but not subsequent medical clearance before returning to play. However, the accuracy of this report could not be confirmed. Other reasons mentioned included being unaware of the requirement to seek medical clearance before returning to play $(13 \%, n=2)$ or that it took too much time to see a medical doctor $(7 \%, n=1$, Table 1$)$.

In contrast, the most frequently mentioned enabler for seeking medical clearance was because they had been instructed to do so - either by the tournament doctor (91\%, $\mathrm{n}=10)$ or their school coach $(9 \%, \mathrm{n}=1)$. The other reasons for seeking medical clearance was because there was concern for the player's well-being as they were still symptomatic.

Table 1: Reasons for seeking or not seeking medical clearance before returning to play

\begin{tabular}{ll}
$\begin{array}{l}\text { Reasons for not seeking medical } \\
\text { clearance } \mathbf{( 4 7 \%} \text {, n=15) }\end{array}$ & \% (N) \\
$\begin{array}{ll}\text { 1.Not necessary, according to: } \\
\text { Parents/player* }\end{array}$ & $80(12 / 15)$ \\
School coach & $92(11 / 12)$ \\
2. Unaware of the requirement & $8(1 / 12)$ \\
3. Too much time & $13(2 / 15)$ \\
\hline
\end{tabular}

Reasons for seeking medical clearance $(53 \%, n=17)$

1. Instructed to do so, by: $65(11 / 17)$

Tournament doctor $91(10 / 11)$

School coach $9(1 / 11)$

2. Concern for player's well-being (symptomatic)

$35(6 / 17)$

*In one case, the parent's interpretation of the tournament doctor's advice was three weeks of break from contact sport, but not subseauent medical clearance before returning to plav.

\section{Discussion}

Roughly half of the concussed players in this study (53\%) sought medical clearance before returning to play, which is more than in a similar study in Australian youth rugby. [5] However, these two studies are not directly comparable. The Australian study [5] had far greater statistical power and examined compliance to the entire GRTP, whereas the present study only focused on one aspect of the GRTP i.e. medical clearance prior to return to play.

In this study, it is important to note that $35 \%$ of these players sought medical clearance because they were symptomatic, which is a positive. A legitimate concern, however, is that an apparently asymptomatic player, who chooses not to seek medical clearance, might not have completely recovered and may still be at risk if returned to full contact rugby too early. For example, once these players are subjected to physical exertion, symptoms might re-emerge. [1] Nonetheless, the majority $(65 \%)$ of players who sought medical clearance were told to do so either by the tournament doctor or their school coach.

Seeking medical clearance was not associated with medical insurance or previous concussion history, which is surprising, but this should be interpreted with caution due to the low sample size of this pilot study.

Despite these low numbers, it is concerning that the main reason cited for not seeking medical clearance was that the parents/player or school coach decided it was unnecessary. Although coaches are directly targeted by the BokSmart rugby safety workshops because of their influence on 
players' injury prevention practices, ${ }^{[4]}$ they did not appear to be positively influential in this pilot sample examining concussion return-to-play behaviours.

The current findings therefore suggest that additional concussion education strategies are required to effectively target medical doctors, players and parents, in addition to coaches and referees. ${ }^{[2]}$

The enablers to seeking medical clearance (Table 1) suggest that the tournament medical doctors who initially diagnosed the concussion are influential in determining return-to-play behaviour. Thus medical doctors who regularly assess sport-related concussions might require tailored concussion education.

Acknowledgements: The researchers would like to thank the tournament medical doctors, nurses and paramedical staff at all the SA Rugby Youth Week tournaments for their assistance in collecting these data. In addition, the researchers would like to thank the players and parents involved in collecting these data.
Conflict of interest: The authors have no conflict of interests to declare.

\section{References}

1. McCrory P, Meeuwisse WH, Aubry M, et al. Consensus statement on concussion in sport: the 4th International Conference on Concussion in Sport held in Zurich, November 2012. Br J Sports Med 2013;47(5):250-258. [http://dx.doi.org/10.1136/bjsports-2013-092313] [PMID: 23479479]

2. Viljoen W, Patricios J. BokSmart - implementing a National Rugby Safety Programme. Br J Sports Med 2012;46(10):692-693. [http://dx.doi.org/10.1136/bjsports-2012-091278][PMID: 22611147]

3. McFie S, Brown J, Hendricks S, et al. Incidence and factors associated with concussion injuries at the 2011 to 2014 South African Rugby Union Youth Week tournaments. Clin J Sport Med; Published Ahead of Print Post Author Corrections: December 22, 2015. [http://dx.doi.org/10.1097/JSM.0000000000000276]

4. Brown JC, Viljoen W, Lambert MI, et al. The economic burden of time-loss injuries to youth players participating in week-long rugby union tournaments. J Sci Med Sport 2015;18(4):394-399. [http://dx.doi.org/10.1016/j.jsams.2014.06.015] [PMID: 25138043]

5. Hollis SJ, Stevenson MR, McIntosh AS, et al. Compliance with return-toplay regulations following concussion in Australian schoolboy and community rugby union players. Br J Sports Med 2012;46(10):735-740. [http://dx.doi.org/10.1136/bjsm.2011.085332] [PMID: 21705397] 